\title{
Factors Influencing The Participation Of Nurses In Knowledge-Sharing Within Mobile Instant Messaging Based Virtual Communities Of Practice: A Qualitative Content Analysis
}

This article was published in the following Dove Press journal:

Advances in Medical Education and Practice

\author{
Saeed Babajani-Vafsi' \\ Jamileh Mokhtari Nouri ${ }^{1,2}$ \\ Abbas Ebadi ${ }^{1,3}$ \\ Mitra Zolfaghari ${ }^{4}$ \\ 'Nursing Management Department, \\ Faculty of Nursing, Baqiyatallah \\ University of Medical Sciences, Tehran, \\ Iran; ${ }^{2}$ Medicine, Quran and Hadith \\ Research Center, Baqiyatallah University \\ of Medical Sciences, Tehran, Iran; \\ ${ }^{3}$ Behavioral Sciences Research Center, \\ Life Style Institute, Baqiyatallah University \\ of Medical Sciences, Tehran, Iran; \\ ${ }^{4}$ Nursing and Midwifery Care Research \\ Center, Department of Electronic \\ Learning in Medical Sciences, Virtual \\ School, Tehran University of Medical \\ Sciences, Tehran, Iran
}

Introduction: The emergence of mobile instant messaging (MIM) based virtual communities of practice (VCoPs) has provided new opportunities for nurses to share their knowledge and promote collaborative learning. This study was conducted with the aim of exploring the factors influencing nurses' participation in knowledge-sharing within MIM-based VCoPs. Material and methods: This is a qualitative study conducted in Tehran, Iran, between April 2017 and July 2018. The participants were 18 nurses that selected through purposeful sampling technique; then, in-depth and semi-structured interviews were conducted with them. Data was analyzed using conventional content analysis based on Graneheim and Lundman (2004). Accordingly, all interviews were transcribed and read several times; then, meaning units were identified from the transcribed text based on the aim of the study and codes were extracted from them. Finally, the codes were classified into categories and themes.

Results: A total of 26 sub-categories, seven categories, and two themes were extracted. Motivations for nurses' participating in knowledge-sharing activities within MIM-based VCoPs included the theme "Stimuli for professional interactions" with three categories: "The individual drives", "Attractive interactive environment", and "User-friendly media". On the other hand, participation barriers included the theme "Impediments for professional interactions" with four categories of "Individual hindrances", "Social harm", "Unprofessional interactive environment" and "Undesirable media".

Conclusion: The findings of this exploratory study indicated that individual, social and technological factors as well as factors associated with the virtual-community interactive environment could influence nurses' participation in knowledge-sharing within MIM-based VcoPs as motivations and barriers. The insights obtained from this study can be a guide for administrators and educators in the nursing profession to facilitate and enhance nurses' participation in knowledge-sharing within MIM-based VCoPs by strengthening motivations and minimizing barriers.

Keywords: social media, mobile applications, social learning, nursing education research, knowledge management

\section{Introductions}

Concurrent with the growing changes in healthcare settings and technological advancements, nurses need to improve their professional knowledge and competencies to provide safe and effective care in complex healthcare settings. ${ }^{1-3}$ In
Correspondence: Jamileh Mokhtari Nouri Nursing Management Department, Faculty of Nursing, 6th floor, Baqiyatallah University of Medical Sciences, Mulla Sadra Street, Vanak Square, Tehran, Iran Tel +98 2l 82455493

Fax +982188600947

Email mokhtari@bmsu.ac.ir 
recent years, the emphasis has been placed on the role of interpersonal interactions in learning to enhance knowledge and skills; ${ }^{4}$ hence, knowledge-sharing is considered one of the most effective and modern strategies for collaborative learning. ${ }^{2,5}$

The tacit knowledge is often perceptual, inexplicable, and not easily transferable. ${ }^{6}$ Therefore, the sharing of such knowledge requires facilitating interactions and networking-based externalization using information and communication technology (ICT). ${ }^{6,7}$ The advent of cyberspace resulted from the advances in ICT has provided new capabilities and capacities for collaborative learning. Therefore, cyberspace has become a powerful virtual environment that provides new opportunities for the achievement of educational objectives. ${ }^{8}$ Evidence has suggested that a growing trend has emerged towards the use of social media and a new generation of these technologies, particularly mobile instant messaging (MIM) platforms, ${ }^{2,4,6,9,10}$ such as WhatsApp, Viber, and Telegram, among individuals and healthcare providers including nurses. ${ }^{4,11}$ Telegram is the most popular social media in Iran; ${ }^{12}$ therefore, most interactions among Iranian nurses within social networks occur in this context.

Today, social media contributes to increasing interactions and creating professional virtual communities, including virtual communities of practice (VCoPs). ${ }^{2}$ VCoPs are online communities formed around common interests of individuals in terms of their skills. ${ }^{13,14}$ Indeed, members of VCoPs share their tacit knowledge and discuss skills, thereby co-creating new knowledge in these online interactions. ${ }^{2,14}$

Previous evidence has indicated that members' participation was limited in knowledge-sharing activities within virtual communities. $^{5,15}$ This issue has remained a major concern and a challenge for administrators. ${ }^{16}$ Although the survival and successful performance of a VCoP have been dependent on the dynamics and active participation of its members, ${ }^{17}$ factors affecting the participation of members in knowledge-sharing activities have still remained unclear. $^{6,18,19}$

On the other hand, despite the differences in patterns of using private and voluntary virtual-communities with those communities affiliated with corporations and organizations in sharing knowledge, ${ }^{20}$ evidence indicates that non-business and non-organizational online communities have not been examined in previous studies. ${ }^{19}$ Further, it is essential to investigate these virtual communities in other contexts given the impact of cultural differences on the knowledge- sharing process. ${ }^{5}$ In spite of the previous studies in this area, these studies often have conducted with a quantitative approach. In addition, most previous studies on virtual communities have been conducted on the context of social networking sites (SNS). Therefore, a new perspective on factors influencing nurses' participation in knowledge-sharing within emerging MIM-based VCoPs is necessitated through an exploratory and qualitative approach. ${ }^{21}$ To help fill the existing gap, this study aimed to explore the factors influencing nurses' participation in knowledge-sharing activities within the voluntary MIM-based VCoPs.

\section{Materials And Methods Study Design}

According to the naturalistic paradigm, there are multiple realities for each phenomenon that subjectively form in the minds of individuals, and the unique experiences of each individual involved in a situation can influence the formation of the reality. Therefore, to fulfill the aim of the study, a qualitative and exploratory approach was used as the most appropriate strategy to the in-depth understanding of the participants' experiences associated with factors influencing their knowledge-sharing activities within MIM-based VCoPs. ${ }^{21,22}$ This study has been conducted in Tehran, Iran, between April 2017 and July 2018.

\section{Ethical Considerations}

To observe ethical considerations, candidate individuals were assured that both entering and continuing participation in this study were optional. Additionally, written informed consent was obtained from participants. Furthermore, they were assured about the confidentiality and anonymity principles before each interview. Ethical considerations were based on, but not limited to, the guidance provided by the Ethics Committee. For example, one participant's feelings were hurt by recalling the loss of her job position resulted from the disclosure of her posted messages. Therefore, beyond the Ethics Committee guidance, the interviewer postponed the interview, empathized with him, and allowed him to express his feelings.

\section{Study Setting}

Study settings were some of the nursing schools in medical sciences universities, as well as, various clinical wards including emergency, internal, surgical, plus intensive-care units, in some private and governmental hospitals in Tehran, Iran. 


\section{Participants And Sampling Technique}

The study population included both specialist and general nurses who were members of the VCoPs non-affiliated with organizations on the Telegram platform. These VCoPs included virtual groups created around clinical skills such as intensive care, wound care and cardiopulmonary resuscitation (CPR). Participants were selected through purposeful sampling technique where individuals who met the inclusion criteria were selected as a participant. The inclusion criteria included members within the available VCoPs from all over Iran qualifying the following criteria: A) at least a Bachelor's degree in nursing; B) at least three years of clinical experience; C) at least five months of experience in at least one of the voluntary nursing-related VCoPs (non-affiliated with organizations or corporations); D) sufficient experience of the phenomenon under study, as well as, the ability to express them; and E) willingness to cooperate with the researcher.

The sampling process continued until data saturation. To increase the diversity of participants, they were selected from both female and male genders, various educational degrees ranging from Bachelor to Ph.D., from all clinical, educational, and managerial fields, as well as from various clinical wards. On the other hand, three individuals who did not have active participation in the VCoPs were selected as negative cases.

\section{Data Collection}

Data collection instrument was the in-depth and semistructured interview conducted individually and face-toface for each participant. All interviews were conducted by the first author, a nursing Ph.D. candidate, who had been trained for qualitative research. The researcher was an anonymous member, as an observer, within some available VCoPs. Interviews were conducted under the supervision of the research team who were expert in qualitative research. Data was collected from July 2017 to March 2018.

\section{Interview Process}

After selecting the participants, the study process was first explained to them; then the location and time for the interview were determined based on their preferences. Interviews were usually conducted during non-working hours or the least-loaded working hours in a quiet environment, usually in the staff rest room in the clinical settings or at participants' office in universities. The interviews were recorded using an audio recorder with each interview lasting 45-70 mins. The first participant was a male nurse with a master's degree in critical care nursing and worked in the emergency ward. This individual was a member of two VCoPs created around critical care and exhibited different behavior, ranging from an inactive user to an active participant spectrum in each of them; hence, the researcher was curious to know the factors affecting these two different behavioral spectra.

Interviews began with general questions such as "How are the interactions among members of this virtual community throughout a day?" and then, more specific questions were asked including "What has so far encouraged you to share your information, ideas, or experiences with others within this virtual community?" to achieve the main aim of the study. Probing questions were asked to achieve a more in-depth and clearer understanding of participants' statements and to gain access to richer data. For example, "What did you mean by saying this?" Data were analyzed immediately after each interview. Based on the concepts derived from the previous interviews, the rest of the interviews were conducted with the next participants.

\section{Data Analysis}

Given the limited existing theories and research literature on the emerging phenomenon studied, conventional content analysis based on Graneheim and Lundman (2004) was used for data analysis. ${ }^{23}$ Accordingly, all interviews were transcribed immediately after each recording. The transcripts were read several times to make a comprehensive sense of their content; then, according to the aim of the study, meaning units were identified and initial codes were extracted. Finally, the initial codes, based on their similarities and differences, were classified into more abstract classes (categories and themes). The modification and confirmation of derived concepts, including codes and classes, were performed by the research team. Examples of how the extraction and abstraction of one of the themes derived from codes are summarized in Table 1.

The initial classes were formed after interviewing the third participant. The saturation of data and classes was achieved after interviewing the 14th participant. Four complementary interviews were conducted to achieve greater comprehensiveness and ensure data saturation. Interviews were conducted on two of the participants for the second time to clarify the ambiguity of the previous interview. MaxQDA-11 software was used to facilitate data organization. 
Table I Examples Of How To Extract A Theme From Codes

\begin{tabular}{|c|c|c|c|}
\hline Codes & Sub-Categories & Categories & Theme \\
\hline $\begin{array}{l}\text { The need to be seen by others, The need to be recognized by others, The } \\
\text { need to be admired by others, The need to solve personal problems }\end{array}$ & Psychosocial needs & \multirow[t]{2}{*}{$\begin{array}{l}\text { The individual } \\
\text { drives }\end{array}$} & \multirow{4}{*}{$\begin{array}{l}\text { Stimuli for } \\
\text { professional } \\
\text { interactions }\end{array}$} \\
\hline $\begin{array}{l}\text { The gratification of helping others, The gratification of participating in social } \\
\text { interactions, The interest in promoting individual knowledge, Psychological } \\
\text { dependence on social networks, Having Persuasive personal beliefs }\end{array}$ & Inner inclinations & & \\
\hline $\begin{array}{l}\text { Having credible members, Having specialized instructors, Having capable } \\
\text { administrators, Providing valuable content }\end{array}$ & $\begin{array}{l}\text { Attractiveness and } \\
\text { credibility of virtual } \\
\text { communities }\end{array}$ & \multirow[t]{2}{*}{$\begin{array}{l}\text { Attractive } \\
\text { interactive } \\
\text { environment }\end{array}$} & \\
\hline $\begin{array}{l}\text { Commonalities and similarities among individuals, Friendly atmosphere } \\
\text { within the community, Sense of belonging to the virtual community, Sense of } \\
\text { intimacy with the administrator }\end{array}$ & $\begin{array}{l}\text { Close relationship in the } \\
\text { community }\end{array}$ & & \\
\hline
\end{tabular}

\section{Methodological Rigor}

The criteria offered by Lincoln and Guba (1986) were met for trustworthiness, including credibility, dependability, confirmability, and transferability. ${ }^{24}$ Strategies such as long-term engagement in the research environment, immersion in data, member checking, and peer checking were used for this purpose. Further, all the research stages and subjective processes of the study were recorded carefully and were subjected to peer-review and audit by four external observers. Diversity in the participants was also regarded. Furthermore, the context under study was described as much as possible.

\section{Results}

\section{Characteristics Of Participants}

A total of 20 interviews were conducted with 18 participants. They included 12 males (66.7\%), while the rest were female, with an average age of $35.4 \pm 6.9$ years. Half of them were single and the rest were married. They had 13.1 \pm 6.4 years of work experience, including clinical, academic or managerial, and $22.8 \pm 14.6$ months of membership in related VCoPs. Ten of them had a bachelor's (44.4\%), six master's (33.3\%), and the rest had a Ph.D. degree (22.2\%). The characteristics of the participants are presented in Table 2.

Table 2 The Characteristics Of Participants

\begin{tabular}{|c|c|c|c|c|c|c|c|}
\hline $\begin{array}{l}\text { Number Of } \\
\text { Participants }\end{array}$ & Sex & Age & $\begin{array}{l}\text { Educational } \\
\text { Degree }\end{array}$ & $\begin{array}{l}\text { Marital } \\
\text { Status }\end{array}$ & $\begin{array}{l}\text { Work Experience } \\
\text { (Years) }\end{array}$ & $\begin{array}{l}\text { Role Within } \\
\text { The VCoP }\end{array}$ & $\begin{array}{l}\text { Duration Of Membership } \\
\text { Within The VCoP (Month) }\end{array}$ \\
\hline No.I & Male & 28 & MSc & Single & 5 & User & II \\
\hline No.2 & Male & 36 & $\mathrm{BSc}$ & Married & 15 & Administrator & 13 \\
\hline No.3 & Female & 50 & Ph.D. & Married & 25 & Administrator & 10 \\
\hline No.4 & Male & 29 & $\mathrm{BSc}$ & Single & 8 & User & 8 \\
\hline No.5 & Female & 39 & MSc & Married & 14 & Administrator & 13 \\
\hline No.6 & Male & 33 & MSc & Married & 10 & Administrator & 8 \\
\hline No.7 & Male & 33 & $\mathrm{BSc}$ & Single & 10 & User & 10 \\
\hline No.8 & Male & 32 & BSc & Married & 9 & User & 12 \\
\hline No.9 & Male & 30 & $\mathrm{BSC}$ & Single & 8 & User & 6 \\
\hline No. 10 & Male & 52 & MSc & Married & 30 & Administrator & 36 \\
\hline No.II & Female & 36 & Ph.D. & Single & 16 & User & 26 \\
\hline No. 12 & Male & 42 & Ph.D. & Married & 18 & User & 30 \\
\hline No. 13 & Male & 36 & Ph.D. & Single & 14 & Administrator & 49 \\
\hline No. 14 & Male & 29 & $\mathrm{BSc}$ & Single & 9 & User & 20 \\
\hline No. 15 & Male & 31 & $\mathrm{MSc}$ & Single & 9 & User & 41 \\
\hline No. 16 & Female & 34 & $\mathrm{MSc}$ & Single & 12 & User & 35 \\
\hline No. 17 & Female & 29 & $\mathrm{BSc}$ & Single & 7 & User & 44 \\
\hline No. 18 & Female & 39 & BSC & Married & 17 & User & 40 \\
\hline
\end{tabular}


A total of 26 sub-categories, seven categories, and two themes were extracted during the data analysis. The extracted themes included "Stimuli for professional interactions" and "Impediments for professional interactions".

\section{Stimuli For Professional Interactions}

This theme includes three categories of "The individual drives", "Attractive interactive environment", and "User-friendly media" which will be described as follows:

\section{The Individual Drives}

This category, which has emerged as one of the major categories, included the sub-categories of "Profitability expectation", "Necessity and compulsion", "Empowers", "Sufficient time", "Inner inclinations", and "Psychosocial needs."

From the participants' perspective, profitability expectation was the expectation of receiving rewards including gaining outer rewards, such as material rewards, and inner rewards, such as being respected or encouraged by others. Individual necessities or compulsion (external forces such as being recalled by the administrator for contributing to an online activity) was also considered as a trigger for users to engage in VCoPs. Having sufficient time and capabilities, such as enough knowledge and experience, high self-confidence, and time management skills, were the other motivations for users studied to participate in knowledge-sharing activities.

The gratification of participating in social interactions, the interest in promoting individual knowledge, psychological dependence on social networks, having persuasive personal beliefs (such as religious beliefs), and the gratification of helping others also reflected the inner inclinations encouraging members to share knowledge in the VCoPs. In this regard, one of the participants stated: "I will eagerly comment within the virtual community if I understand that group members need my information." (Participant No.12)

From the perspective of participants, psychosocial needs included the need to be seen by others, the need to be recognized by others, and the need to solve personal problems. For example, a quotation from one of the participants was as follows: "There are some users whose main motive is to show themselves to others; so they argue in the group to be seen and to be recognized by other members." (Participant No.11)

\section{Attractive Interactive Environment}

This category consisted of two sub-categories including: "Attractiveness and credibility of virtual communities" and "Close relationship in the community". The participants considered VCoPs as attractive and credible if they had credible members (such as expert individuals) and provided valuable content (including specialized, applicable, relevant, controversial, and up-to-date content).

Close relationships often developed when members found commonalities and similarities among each other. These common points created a friendly atmosphere and a sense of belonging to the virtual community. For example, one of the participants said: "If members of a group feel attachment and belonging to that group as well as its members, they will be more inclined to present their own content." (Participant No.5)

\section{User-Friendly Media}

This category refers to the acceptability and popularity of MIM platforms from the perspective of users. It included two sub-categories of "Attractiveness of social networking platform" and "Convenience of social networking platform". From the perspective of participants, MIM-based social networks were more attractive to members in their early emergence. In other words, with the normalization and reduction of the attractiveness of MIM-technology over time, the participation of individuals within these VCoPs has also declined.

On the other hand, participants were more engaged in MIM platforms that were easy-to-use and more accessible. In this regard, one of the participants stated: "The quick access to specialized groups created on the Telegram application encourages me to share my information with my colleagues in this way." (Participant No.7)

\section{Impediments For Professional Interactions}

This theme, which indicated the barriers of users' participation in the knowledge-sharing processes within VCoPs, included four categories of "Individual hindrances", "Social harm", "Unprofessional interactive environment", and "Undesirable media". The categories are described as follows:

\section{Individual Hindrances}

This concept, which was one of the most important barriers to knowledge-sharing among users studied, referred to factors that physically or mentally inhibit the users' 
participation in the knowledge-sharing activities within VCoPs. These barriers included "The inclination to be a consumer", "Time pressure", "Fear of being judged by others", "Having a secluded character", "Physical-psychological energy discharge", "Cognitive-mental inhibitors", and "Hoarding of knowledge due to competitiveness".

Participants believed that laziness has become more common among users than before; therefore, they prefer to be a consumer of others' shared content rather than produce it themselves. In addition, other reasons mentioned by the participants as barriers of contributing to knowledgesharing activities included lack of time, worry about the inadequacy of knowledge and experiences, a shy and secluded character, and lack of self-confidence. Another barrier was lack of physical-psychological energy caused by factors such as impatience, mental preoccupations, and heavy workload leading to mental and physical exhaustion.

Some participants were not active in the VCoPs due to cognitive-mental inhibitors such as lack of enthusiasm, disbelief in the benefits of online knowledge-sharing, and negative attitudes to cyberspace. In this regard, one of the participants stated: "I do not believe in virtual groups; therefore, I prefer to read educational material from books." (Participant No.16)

Furthermore, some participants preferred to hoard their knowledge because of jealousy, stinginess, or achieving superiority over competitors. For example, one participant declared: "We had a special case of wound care I did not like to share with my colleagues for learning how to treat it because of a sense of jealousy." (Participant No.15)

\section{Social Harm}

This category, which referred to the undesirable effects of virtual communities on the private life of individuals, included sub-categories of "Distrusting others", "Privacy violations", "Disrespectful treatments", and "Disruptions in the personal life". Social harm referred to participants applying violent, impolite, and offensive treatments, the personal bothering by the others, the fear of disclosing private information, the negative effects of virtual communities on the personal life, and the fear of disrupting family life. From the participants' perspective, distrusting others referred to the concern of being harmed by other users, the abuse of information posted by members, and being humiliated by others. For example, one of the participants stated: "My colleagues may inform my boss about the negative points of my posted comments and, ultimately, thereby threatening my job position." (Participant No.15)

\section{Unprofessional Interactive Environment}

This category referred to the non-professional VCoPs from the participants' perspective, and included three sub-categories of "Inappropriate content", "Disordered virtual communities" and "Scientific level disparities".

Participants noted factors such as anarchy in VCoPs, sharing long content or prolongation of discussions, and the scientific level disparities among members as barriers to participation in knowledge-sharing activities. From users' point of views, inappropriate content consisted of non-scientific, invalid, and useless content and uninteresting topics. Participants believed that inappropriate content referred to a content which was ineffective, non-applicable, irrelevant, and non-original (such as content copied from other groups or channels). Furthermore, the presentation of usual cases, rather than challenging, rare, and specific cases, was considered as other barriers of engagement in knowledge-sharing within VCoPs. For example, one of the participants' statements was as follows: "I myself do not read and share posts that are shared without any references.” (Participant No.13)

\section{Undesirable Media}

This category included sub-categories of "Outdated technologies" and "Technological difficulties". Participants referred to reducing competitive advantages of some of MIMs due to their outdated technology as technological obstacles. Other technological obstacles mentioned by the participants were technological difficulties. These difficulties included software malfunctions, disruption of social networking platforms, low speed of platforms, and social media filtering by the government. For example, one of the related quotations of the participants was as follows: "When the Telegram was filtered, my access to the groups was restricted and I could not access those groups." (Participant No.17)

\section{Discussion}

The present study was conducted to explore the factors influencing the participation of nurses in knowledge-sharing activities within MIM-based VCoPs. Two themes extracted during the data analysis. Motivations included the theme of "Stimuli for professional interactions" with three categories of "The individual drives", "Attractive interactive enviromment", and "User-friendly media". On the other hand, the barriers included the theme of "Impediments for professional interactions" with four categories of "Individual hindrances", "Social harm", "Unprofessional interactive environment", and "Undesirable media". 
The present results revealed that the individual drives were one of the most important motivations for the participation of members in MIM-based VCoPs. Indeed, both human and social dimensions are always stronger than any other dimension for knowledge-sharing activities. ${ }^{6}$ The need to be seen and recognized by administrators and other members was another motivation for users' engagement in the VCoPs. Wasko and Faraj (2005) found that users tend to participate actively in online communities without instantaneous mutual expectations if they understand that knowledge-sharing increases their reputation and occupational credibility. ${ }^{25}$

Additionally, the gratification of helping others was a strong motivation to engage participants in knowledgesharing activities. Although some evidence indicated that the enjoyment in helping others does not facilitate participation in social media-based knowledge sharing, ${ }^{20}$ much evidence suggested that humanitarian considerations (such as pleasure in helping others) can be one of the most important motivations for users to share knowledge with virtual communities' members. ${ }^{2,5,25}$

Profitability expectation was another motivation for participants to share their knowledge in the VCoPs. Previous studies suggested whenever the perceived benefits (rewards) are greater than or equal to the costs (efforts), users are more likely to contribute to the knowledge-sharing activities within virtual communities. ${ }^{25}$

Some participants did not perform a satisfactory activity in the VCoPs because of being worried about their inadequate knowledge and/or fear of being judged by others. Indeed, fear is one of the most important barriers to knowledge-sharing behavior. ${ }^{5}$

Hoarding knowledge due to competition among individuals was another barrier of members' active contribution in the VCoPs. Since staff considers knowledge as a private personal capital and competitive advantage, ${ }^{25}$ knowledge-hoarding has been considered as one of the primary reasons for users' unwillingness to share their knowledge. ${ }^{26}$ Indeed, knowledge-sharing in virtual communities where members highly compete for better job opportunities can be more limited. ${ }^{27}$

The social harm such as worries about the abuse of posted messages or being harmed by others were another interpersonal and societal barrier for the participants' contribution to knowledge-sharing within VCoPs. Consistent with the findings of this study, previous studies found that lack of trust among individuals and worry about privacy violation were the key barriers to knowledge-sharing activities within virtual communities. ${ }^{5,18,25}$ Previous evidence suggested that sharing long topics and prolongation of discussions were barriers to participating in the knowledge-sharing process within $\mathrm{VCoPs},{ }^{28}$ which was in accordance with the findings of this study.

Technological factors, as the infrastructure of virtual communities, play an important role in encouraging members to share knowledge. ${ }^{5}$ The participants considered the technological issues as factors affecting their contribution to knowledge-sharing activities within the VCoPs. Previous studies revealed the technological factors including user-friendliness, availability, functionality, usability of the platform structure, and speed of the platform, as important factors in the engagement of users in the knowledge-sharing activities within virtual communities. ${ }^{5,9,28}$ On the other hand, based on present study and previous evidence, the technological problems were at the same time considered as one of the barriers of the users' engagement within VCoPs. ${ }^{5}$

According to insights obtained from the present study, educators and administrators will be able to adapt their strategies to facilitate collaboration and promote interactive learning among members of MIM-based VCoPs. These modifications could include strengthening motivations and removing barriers of members' participation. In addition, this study highlighted that individual factors are one of the most important factors influencing the nurses' participation studied within MIM-based VCoPs. Therefore, educators and administrators should pay particular attention to the individual aspects of members of these virtual communities. On the other hand, the results of this study can be applied to designing unique questionnaires on members' participation in the knowledge-sharing within MIM-based VCoPs.

As with any qualitative research, this study has some limitations. Since this study was qualitative, its findings may have been affected by the researcher's subjective interpretations and biases. Therefore, to minimize these effects, the researcher, as well as the research team, attempted to ignore their previous knowledge and prejudgment about the phenomenon studied. As well as, the interpretations and findings obtained from the data were discussed with other members of the research team and supervisors in each stage of the study. On the other hand, the VCoPs studied included not only nurses but also members of other health care professions; however, this study was limited to exploring the nurses' experiences. Therefore, future studies in this area on other health care 
professions and in other contexts could extend our understanding of the factors that influence individuals' participation in knowledge-sharing activities within MIM-based VCoPs.

\section{Conclusions}

This study explored the motivations and barriers of the nurses' participation studied in knowledge-sharing activities within MIM-based VCoPs. According to the results of this study, motivations of nurses' participating in knowledgesharing activities included individual and technological motivators and motivators associated with virtual communities. In contrast, barriers included individual, social, and technological barriers and barriers associated with virtual communities. Given the importance of tacit knowledgesharing for healthcare professions, especially nursing, insights obtained from this study can provide a guide for educators and administrators in clinical and academic settings to create a more dynamic learning environment for knowledge-sharing within MIM-based VCoPs. The findings of this study indicated that distrusting others is a key barrier for nurses' participation in knowledge-sharing within MIMbased VCoPs. This issue arises some questions in the mind of the researcher that could be an interesting topic for future studies in this area. For example,

What are the antecedents of trusting and distrusting others from the perspective of members of MIM-based VCoPs? What is the VCoPs members' perception of interpersonal trust within small groups compared to super groups? What are the strategies and challenges of administrators to enhance trust among MIM-based VCoPs members?

Answering these questions with an exploratory approach can provide a deeper and broader insight into trust as one of the key determinants of individuals' participation in knowledge-sharing activities within MIM-based VCoPs.

\section{Ethics Approval}

This study approved by the Ethics Committee of Baqiyatallah University of Medical Sciences (IR.BMSU. rec.1395.227).

\section{Acknowledgments}

The present study resulted from a Ph.D. thesis in nursing at Baqiyatallah University of Medical Sciences (approval code: 24/416 Dated 15.06.2015). The authors would like to express their gratitude to all the participants, as well as those who assisted us with this research.

\section{Author Contributions}

Saeed Babajani-Vafsi generated the idea and designed the study, as well as, gathered data under the supervision of the research team. All authors contributed to data analysis, drafting or revising the article, gave final approval of the version to be published, and agree to be accountable for all aspects of the work.

\section{Disclosure}

The authors report no conflicts of interest in this study.

\section{References}

1. Roux G, Halstead JA. Issues and Trends in Nursing. Jones \& Bartlett Learning; 2017:31-55.

2. Murphy J, Goossen W, Weber P Forecasting Informatics Competencies for Nurses in the Future of Connected Health: Proceedings of the Nursing Informatics Post Conference 2016; Amsterdam: IOS Press; 2017; 232:9-41. doi:10.3233/978-1-61499738-2-1

3. Peate I, Wild K. Nursing Practice: Knowledge and Care. John Wiley \& Sons; 2018:9-57.

4. Bradshaw M, Hultquist BL. Innovative teaching strategies in nursing and related health professions. Jones \& Bartlett Publishers. 2016;3-13.

5. Razmerita L, Kirchner K, Nielsen P. What factors influence knowledge sharing in organizations? A social dilemma perspective of social media communication. J Knowl Manage. 2016;20(6):1225-1246. doi:10.1108/JKM-03-2016-0112

6. Panahi S, Watson J, Partridge H. Conceptualising social media support for tacit knowledge sharing: physicians' perspectives and experiences. $J$ Knowl Manage. 2016;20(2):344-363. doi:10.1108/JKM-06-2015-0229

7. Razmerita L, Kirchner K, Nabeth T. Social media in organizations: leveraging personal and collective knowledge processes. $J$ Organizational Computing Electron Commerce. 2014;24(1):74-93. doi:10.1080/10919392.2014.866504

8. Sadeghi SH. Training in cyberspace. In: Janusz Kacprzyk, editor. Pathology of Learning in Cyber Space. Cham: Springer; 2019:39-53. doi:10.1007/978-3-319-91449-7_3

9. Schmitt TL, Sims-Giddens SS, Booth RG. Social media use in nursing education. Online J Issues Nurs. 2012;17:3. doi:10.3912/OJIN. Vol17No03Man02

10. Pimmer C, Brühlmann F, Odetola TD, Dipeolu O, Gröhbiel U, Ajuwon AJ. Instant messaging and nursing students' clinical learning experience. Nurse Educ Today. 2018;64:119-124. doi:10.1016/j. nedt.2018.01.034

11. Edge W. Nursing professionalism: impact of social media use among nursing students. $J$ Healthc Commun. 2017;2(3):1-2. doi:10.4172/ 2472-1654.100068

12. Akbari A, Gabdulhakov R. Platform surveillance and resistance in Iran and Russia: the case of Telegram. Surveill Soc. 2019;17(1/2):223-231. doi:10.24908/ss.v17i1/2.12928

13. Wang J, Zhang R, Hao J-X, Chen X. Motivation factors of knowledge collaboration in virtual communities of practice: a perspective from system dynamics. J Knowl Manage. 2019;23(3):466-488. doi:10.11 08/JKM-02-2018-0061

14. McLoughlin C, Patel KD, O'Callaghan T, Reeves S. The use of virtual communities of practice to improve interprofessional collaboration and education: findings from an integrated review. J Interprof Care. 2018;32 (2):136-142. doi:10.1080/13561820.2017.1377692

15. Javadpour A, Samiei S. Motivation and barriers to participation in virtual knowledge-sharing communities of practice. Manage Sci Lett. 2017;7(2):81-86. doi:10.5267/j.msl.2016.11.011 
16. Paek H-J, Hove T, Jung Y, Cole RT. Engagement across three social media platforms: an exploratory study of a cause-related PR campaign. Public Relat Rev. 2013;39(5):526-533. doi:10.1016/j.pubrev. 2013.09.013

17. Ziegler M. Building A Virtual Community of Practice: A QuasiExperimental Design Study. University of Phoenix; 2016.

18. Cleveland S, Ellis TJ. Rethinking knowledge sharing barriers: a content analysis of 103 studies. Int J Knowl Manage. 2015;11 (1):28-51. doi:10.4018/IJKM.2015010102

19. Mojdeh S, Head M, El Shamy N. Knowledge sharing in social networking sites: how context impacts individuals' social and intrinsic motivation to contribute in online communities. AIS Trans Human Comput Interact. 2018;10(2):82-104. doi:10.17705/1 thci.00105

20. Rode H. To share or not to share: the effects of extrinsic and intrinsic motivations on knowledge-sharing in enterprise social media platforms J Inf Technol. 2016;31(2):152-165. doi:10.1057/jit.2016.8

21. Fitzpatrick JJ, Wallace M. Encyclopedia of nursing research. Springer Publishing Company; 2006: 423-424.

22. Hays DG, Singh AA. Qualitative inquiry in clinical and educational settings. New York: Guilford Press. 2011:6-55.
23. Graneheim UH, Lundman B. Qualitative content analysis in nursing research: concepts, procedures and measures to achieve trustworthiness. Nurse Educ Today. 2004;24(2):105-112. doi:10.1016/j.nedt.2003.10.001

24. Lincoln YS, Guba EG. But is it rigorous? Trustworthiness and authenticity in naturalistic evaluation. New Directions Eval. 1986;1986(30):73-84. doi:10.1002/ev.1427

25. Wasko MM, Faraj S. Why should I share? Examining social capital and knowledge contribution in electronic networks of practice. MIS Q. 2005;29(1):35-57. doi:10.2307/25148667

26. Holten A-L, Robert Hancock G, Persson R, Marie Hansen Å, Høgh A. Knowledge hoarding: antecedent or consequent of negative acts? The mediating role of trust and justice. J Knowl Manage. 2016;20 (2):215-229. doi:10.1108/JKM-06-2015-0222

27. Muqadas F, Rehman M, Aslam U, Ur-Rahman U. Exploring the challenges, trends and issues for knowledge sharing: a study on employees in public sector universities. VINE J Inf Knowl Manage Syst. 2017;47(1):2-15. doi:10.1108/VJIKMS-06-2016-0036

28. Paroutis S, Al Saleh A. Determinants of knowledge sharing using Web 2.0 technologies. J Knowl Manage. 2009;13(4):52-63. doi:10. $1108 / 13673270910971824$

\section{Publish your work in this journal}

Advances in Medical Education and Practice is an international, peerreviewed, open access journal that aims to present and publish research on Medical Education covering medical, dental, nursing and allied health care professional education. The journal covers undergraduate education, postgraduate training and continuing medical education including emerging trends and innovative models linking education, research, and health care services. The manuscript management system is completely online and includes a very quick and fair peer-review system. Visit http://www.dovepress.com/testimonials.php to read real quotes from published authors. 